Aus dem Anat. Inst. d. Med. Fakultät, Univ. Okayama

(Vorstand: Prof. M. SEKI).

\title{
Beobachtung der durch Fixierung hervorgerufenen Veränderungen der Bindegewebszellen unter dem Phasenkontrastmikroskop.
}

\author{
固定により起る結織細胞の変化の位相差鏡検。
}

\author{
Akira HIRABAYASHI 平 林朗.
}

(Eingegangen am 28. Februar 1955.)

Es gibt eine schöne zusammenfassende Darstellung von TELLYESNICZKY (1926) über die Veränderungen der Zellen und Gewebe nach der Fixierung. Über die Veränderungen der Zellen während der Fixierung wissen wir aber nicht viel. STRANGEWAY und CANTI (1928) haben im Dunkelfeld die durch Fixierungsreagenzien hervorgerufenen Veränderungen der Zellen beobachtet. Die Veränderungen der feinen Zellstrukturen konnten dabei nicht wahrgenommen werden. Dies wurde erst ermöglicht durch das Phasenkontrastverfahren. So hat ZOLLINGER (1948 a) die mit Formalin versetzten überlebenden Zellen aus der Froschniere im Phasenkontrastmikroskop untersucht und festgestellt, daß schon einige Sekunden nach der Formalinversetzung eine geringe Schrumpfung des Kerns und eine Verdichtung des Kernmembran hervogebracht werden. Auch stellte er (1948 b) fest, daß die Mitochondrien der Leberzellen nach der Versetzung 10\%iger Formalinlösung ohne irgend eine Gestaltsänderung kleiner werden, und daß bei der Anwendung von 95\% igem Alkohol, Aceton und 3\% igem Kaliumbichromat etwa gleichartige Veränderungen erfolgen. Außerdem liegen noch einige phasenkontrastmikroskopische Untersuchungen über die Zellveränderungen während der Fixierung vor. Die Untersuchungen wurden aber meist an verschiedenen Zellen vorgenommen, und die einzelnen Befunde wurden nachher zusammengefasst. So war es auch bei der Untersuchung von IHNUMA (1952) an den Leberzellen von einem Fische. Es gibt anscheinend nur eine einzige Arbeit von BUCHSBAUM (1948) über die Milzzellen des Tritons, die von den Veränderungen bei ein und derselben Zelle handelt. Im folgenden sollen die phasenkontrastmikroskopischen Untersuchungen über die während der Einwirkung verschiedener Fixierungsmittel stattfindenden Veränderungen der einer genauen Beobachtung zugänglichen Bindegewebszellen besprochen werden.

\section{Material und Methode.}

Ein kleines Stückchen des subkutanen Bindegewebes aus dem Rücken 
der Maus wurde sorgfältig in der LOCKEschen Flüssigkeit auf dem Objektglas ausgebreitet. Auf die beiden Ränder: des Gewebshäutchens legte man zwei Celloidinstreifen von etwa $30 \mu$ Dicke, $2 \mathrm{~mm}$ Breite und $10 \mathrm{~mm}$ Länge parallel auf, setzte dann das Deckglas auf und kittete nur die zwei gegenüberstehenden Ränder des letzteren auf dem Objektglas mit Vaseline. Die Celloidinstreifen dienten dazu, die Bewegung des Gewebshäutchens zu verhindern. Man beobachtete die Bindegewebszellen im Phasenkontrastmikroskop. Nachdem die Zellen photographiert waren, wurde die Flüssigkeit unter dem Deckglas gegen eine Fixierungsflüssigkeit ausgetauscht, indem man auf eine Seite des Deckglases einen Tropfen Fixierungsfüssigkeit legte und aus der anderen Seite des Deckglases die unter demselben vorhandene Elüssigkeit mit Filtrierpapier heraussaugte. Die Veränderungen der Zellen wurden in gewissen Zeitabständen wiederholt photographiert, um schließlich die Zellen mit Eisenhämatein zu färben. Manchmal wurden die Zellen, wenn sie sich lebendig befanden, mit $0.01 \%$ igem Neutralrot, 0 01\% igem Victoriablau, aber auch mit Sudan III gefärbt.

Man verwandte die CHIYODA-Phasenkontrasteinrichtung, und zwar zumeist den mittelstark negativen Phasenkontrast von $90 \times$ Vergrößerung, mitunter aber auch den mittelstark positiven Phasenkontrast derselben Vergrößerung. Als Aufnahmegerät diente eine CHIYODA 35-Kamera. Die Photographien wurden alle in derselben Vergrößerung kopiert.

\section{Ergebnisse.}

Die durch die Fixierungsflüssigkeiten hervorgerufenen Strukturveränderungen der Bindegewebszellen sind in den Abbildungen 1-8 gezeigt. Im folgenden sollen die Abbildungen eingehend erläutert werden.

\section{A. Fibrocyten.}

\section{a) Lebende Fibrocyten.}

Die lebenden Fibrocyten sind, wie in dem rechten Abschnitt der Abb. 1 und in dem unteren Abschnitt der Abb. 5 gesehen werden kann, oft nicht deutlich umrissen, ihre feineren Zellfortsätze sind auch sehr oft schwer zu erkennen. Die Zellkerne sind rundlich oder elliptisch und mit klarer Kernmembran versehen. Im Inneren des Kerns finden sich ein oder zwei hell leuchtende Kernkörperchen, welche sich langsam bewegen. Das Cytoplasma enthält stark leuchtende Fetttöpfchen und blaß aussehende Vakuolen in geringer Zahl.

In der Nähe des Kerns sieht man hell erscheinende körnige, stäbchenförmige und fädige Mitochodrien. Die stäbchenförmigen und fädigen Mitochondrien sind verhältnismäßig schwächer leuchtend, während die Mehrzahl der körnigen und hantelförmigen stärker aufleuchtet. 


\section{b) Zusatz der ZENKERschen Flüssigkeit.}

Zugleich mit dem Hinzutreten der ZENCKERschen Flüssigkeit werden die Fibrocyten etwas kleiner, wobei der Umriß der Zellen häufig undeutlicher hervortretend wird. Der Kern wird auch kleiner. Manchmal kommt ein anderes Kernkörperchen zum Vorschein (vgl. Abb. 1 und 2). Die in der Umgebung des Zellkerns vorhandenen fädigen Mitochondrien vermindern sich.

Nach 30 Min. werden die Zellen etwas deutlicher umrissen; die Kernmembran verdickt sich unregelmäßig und werden zugleich stärker leuchtend. Diese Erscheinungen werden nach 1 Stunde noch ausgesprochener (Abb. 3). Im Verlauf der Zeit läßt der Kern die netzige Struktur immer deutlicher erkennen.

\section{c) Zusatz der 10\%igen Formalinlösung.}

Nach der Formalinfixierung wird das Cytoplasma der Fibrocyten weniger körnig als nach der Fixierung mit der ZENKERschen Flüssigkeit, es wird mehr retikulär. Nach der Formalinfixierung fällt eine beträchtliche Vermehrung der leuchtenden Fähigkeit der Kernmembran auf (Abb. 6 u. 7). Die netzige Struktur des Kerns erscheint auch deutlicher als bei der Fixierung mit der ZENKERschen Flüssigkeit. Die Größe des Kerns bleibt fast gleich.

\section{B. Fibrohistiocyten.}

\section{a) Lebende Fibrohistiocyten.}

Ein lebender länglicher Fibrohistiocyt ist in dem linken Abschnitt der Abb. 1 dargestellt. Die Zellkontur ist etwas schärfer als die der Fibrocyten. Im Cytoplasma finden sich zahlreiche, mehr oder weniger stark lichtbrechende Granula von verschiedener Größe. Im übrigen sind Vakuolen dunkel ausgespart. Der Kern des Fibrohistiocyten ist kleiner als die der Fibrocyten. Er zeigt eine Delle auf der unteren Seite, welche vielleicht durch einen Druck einer Vakuole gebildet ist.

\section{b) Zusatz der ZENKERschen Flüssigkeit.}

Kurz nach dem Austaussch der LOCKEschen Flüssigkeit gegen die ZENKERsche wird die Kontur des Fibrohistiocyten etwas unschärfer. Der Kern fängt an, sich zu verkleinern (Abb. 2). Die Mehrzahl der Granula im Cytoplasma vermindert ihrén Glanz und sieht etwas aufgequollen aus. Nur die größten zwei Schollen leuchten immer noch sehr stark auf.

30 Min. nach dem Hinzusetzen der Fixierungsflüssigkeit werden die Veränderungen der Zelle bedeutend. Nach 1 Stunde verkleinert sich der Zelleib auffallend. Dementsprechend wird der Kern beträchtlich kleiner und zeigt Granula und Netzchen. Die verdickte Kernmembrane leuchtet. 
Die oben erwähnten beiden stark aufgeleuchteten Schollen büßen ihren Inhalt und Glanz sehr ein.

In der linken, unteren Ecke der Abb. 3 kommt ein Fibrohistiocyt in die eingestellte Sehebene und ist klar sichtbar. Er führt mehrere Vakuolen.

c) Zusatz der 10\%igen Formalinlösung.

Drei Fibrohistiocyten kommen nach dem Zusatz der 10\% igen Formalinlösung in die Sehebene und werden nun deutlicher gesehen (Abb. 7). Die Kernmembran scheint stark gefältelt zu sein. Das Cytoplasma sieht netzig-körnig aus.

\section{Histiocyten.}

a) Lebende Histiocyten.

Im oberen Abschnitt der Abb. 5 ist ein Histiocyt dargestellt, welcher aber nicht scharf konturiert ist. Der Kern ist kleiner als derjenige der Fibrocyten und hat reichlich körnige Substanzen. Das Cytoplasma enthält viele Vakuolen und Körnchen von verschiedener Größe.

b) Zusatz der ZENKERschen Flüssigkeit.

Die Veränderungen der Histiocyten sind etwa wie bei den Fibrohistiocyten. Gegenüber nach der Fixierung mit Formalin leuchten hier verschiedene Gebilde schwächer.

c) Zusatz der 10\%iger Formalinlösung.

Einige Minuten nach dem Austausch des Formalins gegen die LOCKEsche Lösung verkleinert sich der Kern ein wenig (Abb. 6). Die Kernmembran wird dabei stark glänzend. Das Innere des Kerns wird weniger körnig und mehr netzig. Im Cytoplasma tritt auch eine ausgesprochene netzige Struktur auf. Nach Ablauf von einer Stunde werden die Veränderungen stärker.

In Abb. 4 und 8 sicht man schließlich die Zellen, die nach der 2stündigen Fixierung mit der ZENKERschen Flüssigkeit bzw. Formalin mit dem Eisenhämateinlack gefärbt und in Xylolbalsam eingeschlossen sind. Die Vergleichung dieser Abbildungen mit den lebenden Zellen in Abb. 1 und 5 veranschaulicht die Unterschiede der Bilder in frischen und Dauerpräparaten.

\section{Ergänzende Betrachtung.}

Die überlebenden Bindegewebszellen aus dem subkutanen Bindegewebe der Maus lassen im unserem Phasenkontrastmikroskop oft keine distinkte Zellkontur erkennen, zeigen aber immer eine sehr deutliche Kernmembran. In den Fibrocyten lassen sich Mitochondrien erkennen. 
Weil sie aber bei der photographischen Auf nahme nicht immer stillstehen, erscheinen sie in den Photographien häufig unklar. Die bei Anwendung negativen Phasenkontrastes leuchtenden Körnchen und Mitochondrien beweisen uns den Reichtum des Lipoides an ihrer Oberfläche, wie es BENSLEY (1937) bei den Leberzellen des Meerschweinchens bemerkt hat. Nach der Fixierung mit der ZENKERschen Flüssigkeit werden sie weniger leuchtend und sogar oft unsichtbar. Dies beruht vielleicht auf der Aufquellung und Auflösung des Lipoides durch die Essigsäure. Die in den Histiocyten beim negativen Phasenkontrast am stärksten lichtbrechenden Gebilde sind bei der Sudan III-Färbung rotorange färbbar.; sie sind also Fẹttropfen. Man kann in dem negativen Phasenkontrastmikroskop dunkle und schwach leuchtende Vakuolen unterscheiden. Die letzteren sind mit lipoidfärbendem Victoriablau färbbar.

Das Cytoplasna der mit Formalin fixierten Bindegewebszellen erscheint unter dem Phasenkontrastmikroskop netzig-körnig, dasjenige der mit der ZENKERschen Flüssigkeit fixierten aber mehr körnig.

\section{Zusammenfassung.}

Ein kleines Stückchen aus dem subkutanen Bindegewebe der Maus wurde zuvor in der LOCKEschen Lösung eingeschlossen. Diese Lösung wurde dann durch eine Fixierungsflüssigkeit ersetzt. Die dabei stattfindenden Veränderungen der Bindegewebszellen wurden mit dem Phasenkontrastverfahren beobachtet und photographiert. Die Präparate wurden schließlich mit Eisenhämatoxylin gefärbt und in Kanadabalsam vergleichend beobachtet.

1. Die bei Anwendung negativen Phasenkontrastes in den lebenden Zellen stark lichtbrechenden Körnchen und Mitochondrien büßen durch die ZENKERsche Flüssigkeit meist mehr oder weniger ihre Helligkeit ein. Der Zelleib und der Kern verkleinern sich dabei bedeutend.

2. Nach der Fixierung mit $10 \%$ iger Formalinlösung zeigt das Cytoplasma eine mehr netzige Struktur. Der Zelleib und der Kern bleiben in diesem Fall fast gleichgroß wie vorher.

\section{内 容 自 抄.}

二十日鼠の皮下結織の小片を取り，Locke 氏液に封入し，位相差顕微鏡 内で観察しながら，封入液を固定液と置き換え，その時の細胞の変化を追 及した，結織細胞が生きている間に負位相差で強く光って見える粒子と糸 粒体は Zenker 氏液の中では輝きを減じて見難くなり，消失するものもあ る。そして胞体と核は著しく小さくなる，10\%ホルマリン溶液での固定の 時は Zenker 氏液固定のとき飞比べて胞形質が粒子状になることが弱く， 
むしろ網状構造をよく現わす，胞体と核はこの場合には殆んど小さくなら ない。

\section{Literatur.}

Bensley, R. R. : On the fat distribution in mitochondria of the guinea-pig liver. Anat. Rec. 69 (1937). - Buchsbaum, R. : Individual cells under phase microscopy before and after fixation. Anat. Rec. 102 (1948). - Innuma, M.: Phase contrast microscopy of liver cells of a fish (Oryzias latipes). II. Changes of intracellular structures of the fresh cursh preparations during the application of fixing solutions. Okajimas Fol. 24 (1952). - Strangeways, T. S. a. R. G. Canti : The living cell in vitro as shown by darkground illumination and the changes induced in such cells by fixing reagents. Quart. J. microsc. Sci. 71 (1928). - Zollinger, H. U.: Alternation in the nuclei of resting and dividing cells induced by means of fixatives, anisotonic solutions, acid and alkali. Amer. J. Path. $24(1948$ a). - The mitochondria and other cytoplasmic constituents under various experimental conditions. Amer. J. Path. 24 (1948 b).

\section{Erklärung der Tafelabbildungen.}

Photographische Aufnahme der Bindegewebszellen aus dem Subkutangewebe der Maus, bei Anwendung negativen Phasenkontrastes. Auch Aufnahmen derselben Zellen im Hellfeld nach der Eisenhämateinlackfärbung und dem Einschließen in Kanadabalsam. Vergr. 1080x.

Abb. 1. Lebende Zellen in der LOCKEschen Lösung. Zwei Fibrocyten (rechts) und ein Fibrohistiocyt (links).

Abb. 2. 5 Min. nach dem Zusatz der ZENCKERschen Flüssigkeit. Die geringgradige Verkleinerung der Zellen und die Abnahme der Helligkeit der Körnchen und Mitochondrien. Die Undeutlichkeit mancher Körnchen und Mitochondrien beruht auf ihrer Bewegung wänhrend der photographischen Aufnahme.

Abb. 3. 1 Stunde nach dem Zusatz der ZENKERschen Flüssigkeit. Beträchtliche Verkleinerung des Zelleibes und des Kernes. Sonst etwa wie bei Abb. 2.

Abb. 4. Obige Zellen im Hellfeld. Eisenhämateinlack-Färbung und Einschließen in Kanadabalsam.

Abb. 5. Lebende Zellen. Ein Fibrocyt (unten) und ein Histiocyt (oben).

Abb. 6. 5 Min. nach dem Zusatz der 10\%igen Formalinlösung. Drei Fibrohistiocyten treten von neuem auf die Sehebene ein und sind deutlicher sichtbar.

Abb. 7. Wie oben, 1 Stunde nach dem Zusatz der 10\%igen Formalinlösung.

Abb. 8. Obige Zellen im Hellfeld. Eisenhämateinlack-Färbung und Einschließen in Kanadabalsam. 
A. HIRABAYASHI

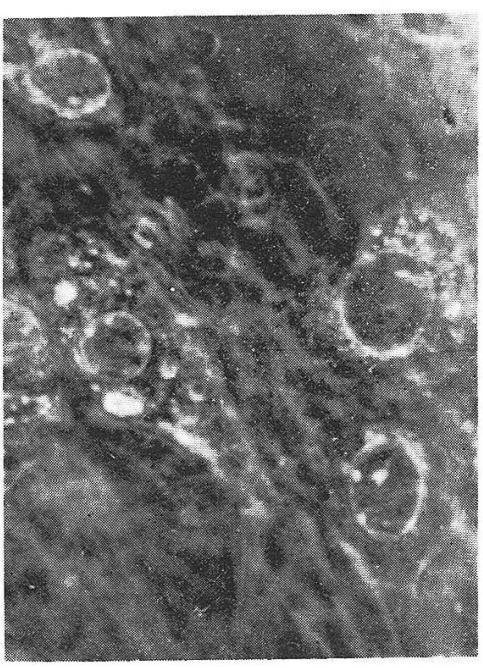

1

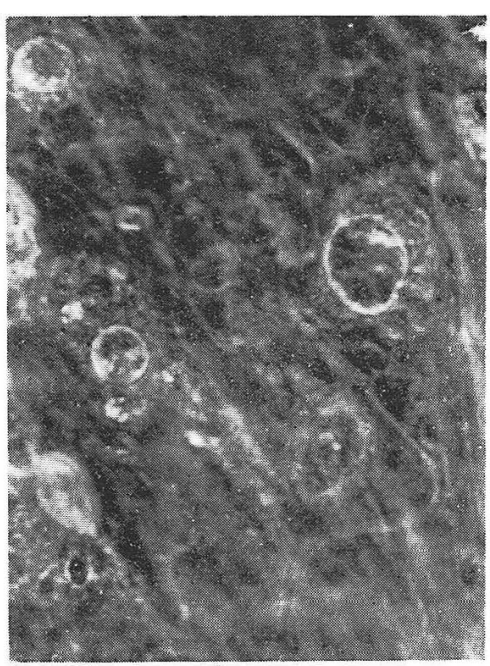

3

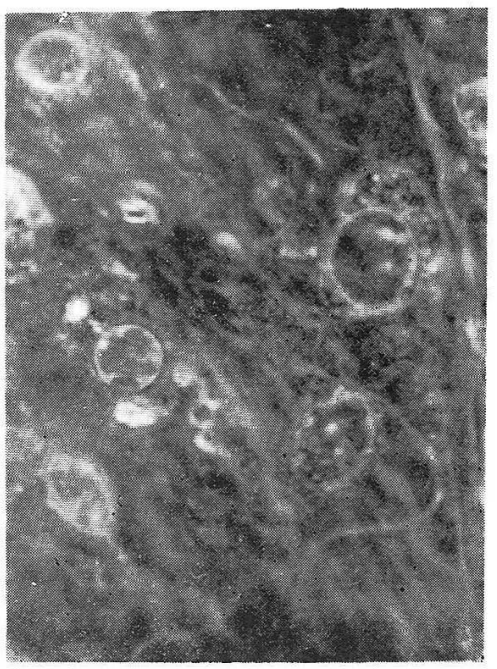

2

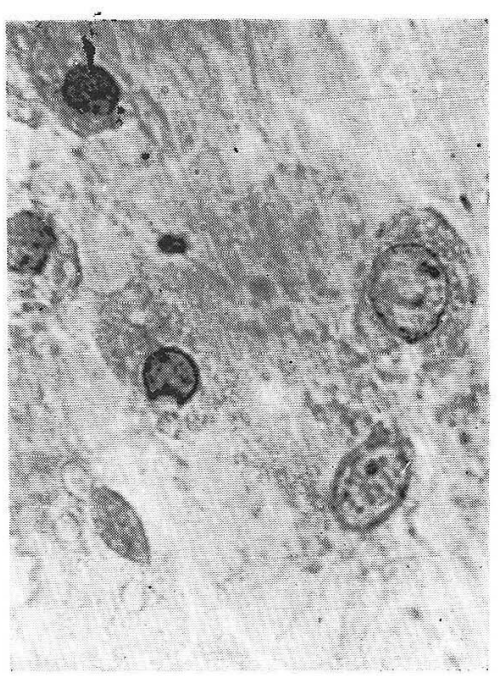

4 


\section{A. HIRABAYASHI}

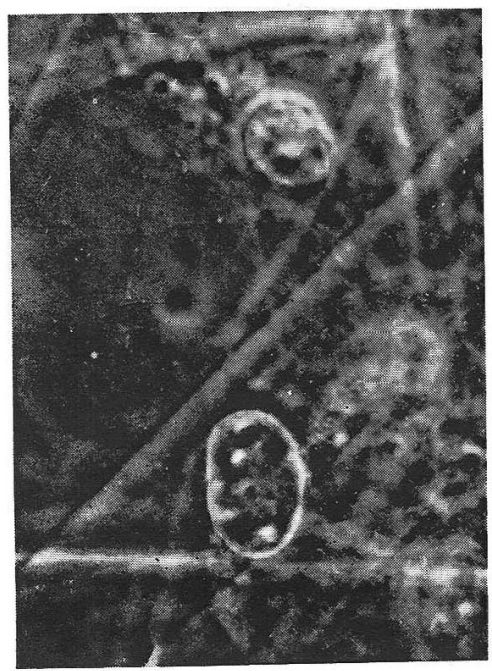

5

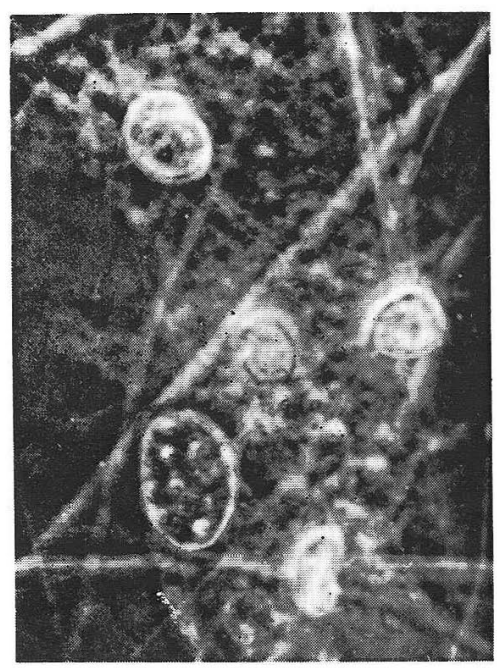

7

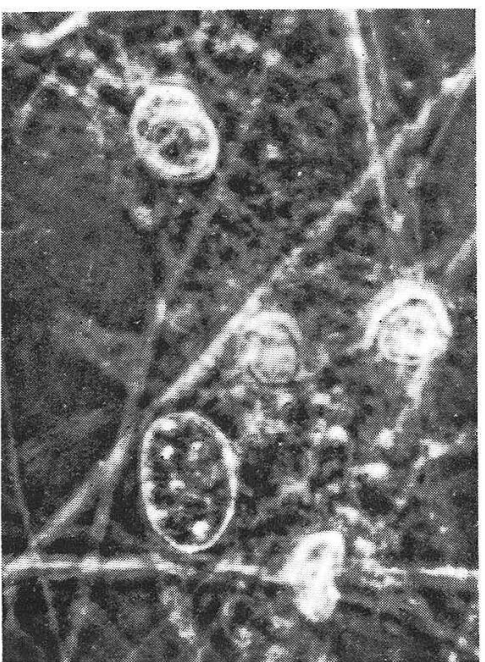

6

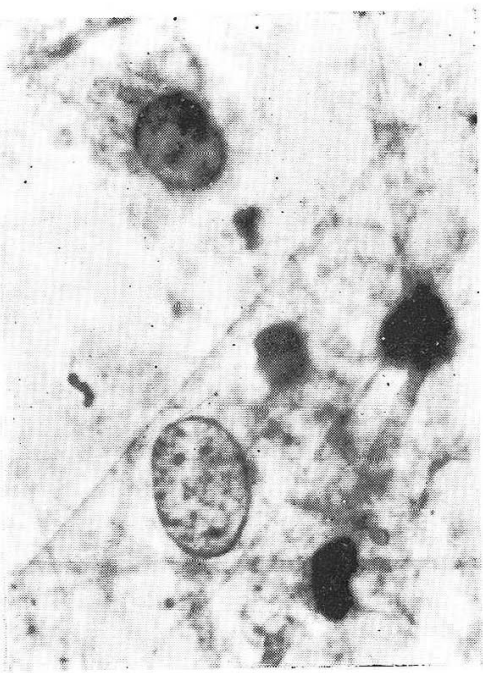

8 